\title{
Analisis SWOT Strategi Pengelolaan Reputasi PT. Cowboy Nusantara Jaya
}

\author{
Yuva Naelana dan S. Bekti Istiyanto \\ Program Studi Magister Ilmu Komunikasi Fakultas Ilmu Sosial dan Ilmu Politik \\ Universitas Jenderal Soedirman \\ Email: naelanayuva@gmail.com, bektiis@yahoo.com
}

\begin{abstract}
ABSTRAK
Kenaikan pada laju permintaaan daging sapi di Indonesia tidak diimbangi dengan peningkatan produksi daging sapi. Permasalahan tersebut mendorong banyak berdirinya perusahaan impor daging sapi, salah satunya adalah PT. Cowboy Nusantara Jaya. Persaingan bisnis yang ketat, menjadikan perusahaan ini perlu merancang rencana strategis dalam mengelola reputasi perusahaan. Pengelolaan reputasi direncanakan secara strategis agar perusahaan dapat memenangkan posisi terbaik di pasar. Tujuan dilaksanakannya penelitian ini adalah penulis ingin mengeksplorasi strategi pengelolaan reputasi yang dilakukan PT. Cowboy Nusantara Jaya berdasarkan analisis SWOT. Metode yang digunakan oleh penulis dalam menyusun penelitian ini adalah deskriptif kualitatif. Dalam penelitian ini penulis menggunakan dua sumber data yakni primer dan sekunder. Penulis melakukan wawancara mendalam kepada tiga informan yang dipilih berdasarkan teknik purposive sampling untuk mendapatkan data primer. Sedangkan, data sekunder penulis peroleh dengan teknik dokumentasi. Hasil penelitian menunjukkan bahwa PT. Cowboy Nusantara Jaya telah melaksanakan beberapa strategi dalam menjaga reputasi induk perusahaan dengan baik. Sebagai anak perusahaan dari PT. Suri Nusantara Jaya yang berada di wilayah Jawa Tengah, PT. Cowboy Nusantara Jaya terus berupaya untuk mengutamakan kepuasan konsumen. Berdasarkan analisis SWOT PT. Cowboy Nusantara Jaya mengelola reputasi perusahaan dengan menjaga kualitas produk, ketersediaan produk, harga produk, serta inovasi pelayanan yang mudah dan cepat untuk para konsumennya.
\end{abstract}

Kata kunci: PT. Cowboy Nusantara Jaya, Reputasi, Analisis SWOT

\section{ABSTRACT}

The increase in the rate of demand for beef in Indonesia is not offset by an increase in beef production. These problems led to the establishment of many beef import companies, one of which was PT. Cowboy Nusantara Jaya. Tight business competition, makes this company need to design a strategic plan in managing the company's reputation. Reputation management is planned strategically so that the company can win the best position on the market. Reputation management is planned strategically 
so that the company can win the best position on the market. The purpose of this research is that the writer wants to explore the reputation management strategy carried out by PT. Cowboy Nusantara Jaya based on SWOT analysis. The method used by the author in compiling this study is descriptive qualitative. In this study the authors used two data sources namely primary and secondary. The author conducted in-depth interviews with three informants selected based on purposive sampling technique to obtain primary data. Whereas, the secondary data obtained by the writer is documentation techniques. The results showed that PT. Cowboy Nusantara Jaya has implemented several strategies in maintaining the reputation of the parent company well. As a subsidiary of PT. Suri Nusantara Jaya in the Central Java region, PT. Cowboy Nusantara Jaya continues to strive to prioritize customer satisfaction. Based on the SWOT analysis of PT. Cowboy Nusantara Jaya manages the reputation of the company by maintaining product quality, product availability, product prices, and easy and fast service innovations for its customers.

Keywords: PT. Cowboy Nusantara Jaya, Reputation, SWOT Analysis

\section{Pendahuluan}

Kebutuhan nutrisi bagi manusia sangat beragam salah satunya adalah nutrisi hewani yang berasal dari daging hewan ternak. Salah satu daging hewan ternak yang digemari untuk dikonsumsi masyarakat Indonesia adalah daging sapi. Seiring dengan laju perekonomian yang kian membaik, permintaan pangan hewani terutama daging sapi juga turut meningkat. Namun meningkatnya laju permintaaan daging sapi di Indonesia tidak diikuti dengan peningkatan produksi daging sapi. Kondisi tersebut akhirnya menyebabkan adanya gap antara ketersediaan dengan permintaan akan daging sapi. Oleh karena itu, akhirnya dilakukan impor daging sapi dari beberapa negara demi memenuhi permintaan konsumen.

Pada tahun 2007 pemerintah mengeluarkan kebijakan melalui Peraturan Menteri Pertanian No. 59/ Permentan/HK.060/8/2007 tentang Percepatan Pencapaian Swasembada Daging Sapi (P2SDS). Kebijakan ini dinilai penting untuk mengoptimalkan dan memperkuat usaha sapi potong rakyat agar terus berkembang dan mengurangi ketergantungan impor daging sapi. Upaya tersebut juga untuk menghindari melambungnya harga daging dipasaran menjadi tidak stabil disaat-saat tertentu. Meskipun begitu data dari Kementerian Pertanian Republik Indonesia menunjukkan 
produksi daging sapi nasional pada 2018 masih pada jumlah 403.668 ton, sedangkan jumlah kebutuhan daging sapi mencapai 663.290 ton. Pemenuhan kebutuhan daging sapi nasional oleh peternak sapi lokal masih pada angka 60,9\%. Oleh sebab itu, hingga saat ini masih dilakukan impor daging sapi sebagai upaya pemenuhan kebutuhan daging bagi masyarakat Indonesia. Hal ini menjadi peluang besar bagi para pelaku bisnis impor daging sapi.

Salah satu perusahaan impor daging sapi terkemuka yang berada di Jakarta yakni PT. Suri Nusantara Jaya. Perusahaan ini mampu berkembang dan tetap bertahan di tengah persaingan kompetitor. Upaya pengembangan bisnis yang dilakukan PT. Suri Nusantara Jaya dilakukan dengan berbagai strategi untuk mempertahankan kualitas dan pelayanan bagi konsumen. Tidak hanya itu, PT Suri Nusantara Jaya hingga saat ini mampu melebarkan sayapnya di kancah nasional bersama anak cabangnyayang tersebar di beberapa wilayah Indonesia.

Dari informasi web PT. Suri Nusantara Jaya atau SNJ, perusahaan ini telah berdiri lebih dari 20 tahun. Menurutnya kesuksesan berada pada prinsip yang telah dipegang sejak dulu, yakni dengan strategi selalu memberikan produk dengan kualitas terbaik, dengan harga yang bersaing, dan layanan yang cepat. Hal ini selaras dengan pengertian reputasi menurut Morley (2002) yang menganggap bahwa reputasi adalah rekam jejak dengan kualitas strategi yang akan berdampak pada kondisi reputasi dari perusahaan berada pada kondisi baik atau buruk, kuat atau lemah. Tidak hanya itu SNJ juga bekerjasama dengan perusahaan BUMN dalam mendukung ketahanan pangan nasional dan menekan harga kebutuhan pokok. Untuk dapat mewujudkan hal tersebut, PT. Suri Nusantara Jaya memiliki beberapa anak cabang yang tersebar di beberapa wilayah, salah satunya PT. Cowboy Nusantara Jaya.

Sebagai anak cabang yang berada di kota kecil tentu PT. Cowboy Nusantara Jaya perlu menjaga reputasi yang telah dimiliki SNJ. Sama dengan SNJ, PT. Cowboy Nusantara Jaya juga perlu menjaga kualitas dan pelayanannya terhadap pelanggan. Untuk menjaga reputasi perusahaan, PT. Cowboy Nusantara juga harus menjaga hubungan dengan karyawan serta pelanggan untuk memelihara kemitraan jangka 
panjang. Merujuk pada pernyataan Dick, Chakravarty dan Biehal (1990) yang menyatakan bahwa reputasi perusahaan secara langsung membentuk kepercayaan pelanggan terhadap produk atau jasa dari perusahaan yang bersangkutan sehingga akan mempengaruhi pelanggan dalam menentukan pilihan.

Upaya menarik kepercayaan pelanggan PT. Cowboy Nusantara Jaya dilakukan dengan strategi pemasaran yang secara langsung akan berpengaruh pada manajemen reputasi. Selaras dengan pengertian reputasi perusahaan menurut Herbig, Millewicz, Golden (1994) yang menyatakan bahwa reputasi perusahaan dapat diraih dengan adanya penghargaan untuk perusahaan yang memiliki keunggulan-keunggulan dan kemampuan perusahaan untukberkembang serta mencipatakan hal baru untuk memenuhi kebutuhan konsumen. Perlu adanya integritas tinggi agar perusahaan dapat memberikan pelayanan terbaik bagi konsumen.Ditambah dengan Direktur Utama PT.Cowboy Nusantara Jaya yang tergolong masih sangat muda, dan tidak hanya memiliki satu jenis bisnis, serta merupakan teman penulis, menjadikan penulis lebih tertarik untuk dapat menganalisa seperti apa strategi yang diterapkan pada perusahaan ini. Dalam upaya memenuhi kebutuhan konsumen, bukan tidak mungkin PT. Cowboy Nusantara Jaya menghadapi kendala dalam mengelola reputasi perusahaan ditengahtengah persaingan ketat bisnis pemasar daging sapi. Inilah yang menjadi urgensi penelitian bagi penulis untuk mengungkap "Strategi Pengelolaan Reputasi PT. Cowboy Nusantara Jaya dengan analisis SWOT".

Berdasarkan latar belakang yang dijabarkan oleh penulis di atas, maka dapat ditarik rumusan masalah dalam penelitian ini adalah: "Bagaimana strategi pengelolaan reputasi PT. Cowboy Nusantara Jaya berdasarkan analisis SWOT?”. Maka penelitian ini bertujuan agar dapat mengeksplorasi strategi pengelolaan reputasi PT. Cowboy Nusantara Jaya dengan analisis SWOT.

Mengutip pernyataan Ardianto (2013) yang menyatakan bahwa reputasi dapat berawal dari identitas korporat sebagai titik pertama yang tercermin dari nama perusahaan, logo, dan tampilan lainnya yang dapat juga berupa non-fisik seperti nilai- 
nilai dan filosofi perusahaan, pelayanan, gaya kerja, dan komunikasi baik dengan pihak internal maupun eksternal.

Reputasi penting bagi sebuah perusahaan, bahkan menjadi keharusan bagi perusahaan untuk membangun reputasinya. Reputasi yang telah berhasil dipupuk akan menjadi dorongan bagi perusahaan dalam memperoleh keuntungan kompetitif. Namun membentuk reputasi perusahaan bukanlah hal yang mudah, perlu rencana yang matang dan strategis. Diikuti dengan prestasi yang dimiliki oleh perusahaan agar dapat menghasilkan kepercayaan para konsumen terhadap perusahaan. Bukan sekedar membangun tetapi reputasi perlu dikelola. Pengelolaan reputasi ini akan menentukan bagaimana kondisi perusahaan menurut penilaian masyarakat terlebih di mata para konsumen.

Seperti pendapat Aldiano yang menyatakan bahwa kondisi baik buruk maupun kuat atau lemah reputasi sebuah perusahaan bergantung pada kualitas pemikiran strategi. Kemudian bagaimana komitmen dalam mencapai tujuan yang telah ditetapkan dengan keterampilan, energi dan rencana komponen program yang akan direalisasikan dan dikomunikasikan sebagai upaya pengelolaan reputasi. Pendapat lain dalam Baines (2004) menyatakan bahwa reputasi perusahaan (corporate reputation) adalah nilai yang melekat seperti otentisitas, kejujuran, tanggung jawab dan integritas yang ditimbulkan dari kepribadian citra perusahaan.

Mengetahui reputasi perusahaan, mendorong manajer untuk berusaha membenahi apa yang kurang dan apa yang salah pada diri perusahaan. Menilai sejauh mana keberhasilan strategi yang dikerahkan dalam mengelola reputasi perusahaan. Biasanya kegiatan ini dilakukan oleh manajer maupun praktisi public relations di sebuah perusahaan. Untuk dapat memenangkan persaingan bisnis, sebuah perusahaan harus dapat mengelola reputasi dengan baik. Reputasi dengan sendirinya akan mempengaruhi bagaimana posisi suatu perusahaan dibandingkan dengan kompetitor. Kaitannya tentu hal ini dapat berdampak pada pendapatan perusahaan dari strategi prioritas yang telah dirancang untuk mencapai tujuan perusahaan baik secara jangka pendek maupun jangka panjang. Pengelolaan reputasi ini lebih dikenal dengan istilah 
manajemen reputasi. Menurut Fambrun (1990) Manajemen Reputasi dapat diidentifikasi melalui:

1. Emotional Appeal: seberapa besar perusahaan tersebut disukai dan dihormati oleh stakeholder-nya (kepercayaan, penilaian dan daya tarik)

2. Products and Services: reputasi akan sejalan paralel dengan kualitas produk dan jasa yang dihasilkan. (produk dan layanan)

3. Vision and Leadership: visi yang jelas dan kepemimpinan yang baik bila diperkokoh dengan etika berprilaku yang baik akan membuat reputasi perusahaan menjadi bagus. (visi dan kepemimpinan)

4. Workplace Environtment: lingkungan kerja yang baik dimana programprogram kesejahteraan pegawai dirumuskan dengan baik juga dapat meningkatkan reputasi perusahaan (tempat dan lingkungan perusahaan)

5. Social Responsibility: perusahaan dengan reputasi yang baik akan memberikan sumbangan sosial untuk masyarakat (mulai merancang strategi ini) tanggungjawab social

6. Financial Performance: reputasi juga terkadang dicermati dari perusahaan yang mempunyai track-record profitabilitas yang baik (kinerja keuangan)

7. Inovasi (terobosan terbaru)

Analisis SWOT merupakan salah satu pendekatan yang paling dikenal oleh para manajer dalam melakukan analisis terhadap perusahaannya. Merujuk pendapat Gitosudarmo (2008) istilah SWOT merupakan perpendekan dari Strengths (kekuatan), Weakness (kelemahan), Opportunities (peluang), dan Treaths (ancaman). Pendekatan ini mengajak seorang manajer untuk berpikir strategis tentang kekuatan apa yang dimiliki, kelemahan apa yang melekat pada perusahaan, melihat kesempatan yang terbuka, dan mempertimbangkan ancaman, hambatan, gangguan bahkan tantangan yang dapat menghadang sewaktu-waktu. Analisis SWOT ini tidak hanya dapat diterapkan pada perusahaan sendiri, tetapi dapat juga digunakan untuk menganalisis 
SWOT dari perusahaan kompetitor agar dapat menyusun rencana strategis dalam pertempuran bisnis.

Pendapat lain muncul dari Ferrel dan Harline (2005) fungsi dari Analisis SWOT digunakan untuk memperoleh informasi dari analisis situasi lingkungan dengan menggolongkannya ke dalam persoalan internal (kekuatan dan kelemahan) dan pokok persoalan eksternal (peluang dan ancaman). Analisis SWOT tersebut akan menjelaskan apakah informasi dapat membantu perusahaan dalam mencapai tujuannya atau justru mengindikasikan adanya rintangan yang harus dihadapi atau diminimalkan.

Gitosudarmo (2008) juga mengemukakan alasan mengapa perlu menerapkan analisis SWOT ini, karena sebuah perusahaan harus berusaha memenangkan pertandingan atau persaingan bisnis melalui cara yang strategis. Berusaha mengalahkan lawan atau pesaing bisnis, agar perusahaan tidak terperosok menempati posisi bisnis yang lebih rendah dalam sebuah kompetisi. Hal tersebut bertujuan agar dapat menang dalam menguasai pasar dan menduduki posisi yang strategis dalam persaingan bisnis. Mengambil langkah strategis dengan memmpelajari kekuatan dan kelemahan yang dimiliki oleh perusahaan maupun lawan, kemudian merumuskan peluang yang terbuka untuk melawan serta memperhatikan dan berusaha untuk menutup diri dari gangguan dan ancaman yang dirancang oleh kompetitor.

Penelitian sebelumnya yang berkaitan dengan pembahasan ini salah satunya telah dilakukan oleh Hakiki Sirait, W.H. Limbong dan Suryahadi pada tahun 2007 dengan judul “Analisis Strategi Pemasaran Daging Sapi pada CV. Duta Mandiri Abadi." Hasil penelitian tersebut menunjukkan bahwa berdasarkan analisis SWOT integritas, strategi yang efektif untuk dilakukan oleh CV. Duta Mandiri Abadi (CV DMA) adalah memperluas serta mempertahankan pasar yang ada, mempertahankan nilai jual produk agar sesuai pasaran, tetap menjaga komitmen manajemen atas kualitas produk, meningkatkan kinerja divisi pemasaran dalam menganalisis permintaan pasar guna memaksimalkan kapasitas produk yang telah ada sebelumnya. Untuk meningkatkan bisnis di masa yang akan datang CV. Duta Mandiri Abadi perlu adanya komitmen dari pihak manajemen untuk mengubah dan merevisi kondisi internal 
dengan menggali potensi yang ada. Perlu memaksimalkan peran serta kinerja divisi pemasaran untuk memperluas segmen pasar.

\section{Metodologi}

Dalam melaksanakan penelitian ini penulis menggunakan metode deskriptif kualitatif agar dapat mengekplorasi lebih jauh strategi pengelolaan reputasi PT. Cowboy Nusantara Jaya dengan analisis SWOT. Merujuk pada pengertian metode kualitatif menurut Moleong (2004) bahwa metode kualitatif dijadikan sebagai prosedur penelitian yang menghasilkan data deskriptif berupa kata-kata atau lisan dari orangorang dan perilaku yang dapat diamati. Penelitian ini mengidentifikasi dan menganalisa objek penelitian dengan menjawab permasalahan.

Mengutip dari apa yang disampaikan Mulyana (2018) bahwa data pada penelitian kualitatif ini memandang perilaku yang tidak dihitung untuk mengetahui hubungannya, seringkali data kualitatif disajikan dalam bentuk gambar, sekumpulan kata-kata, serta bersifat kategori untuk dapat diklasifikasikan ke dalam kategorikategori seperti kelas, individu, objek, atatu proses. Menurut pernyataan Lofland dan Lofland dalam Moleong (2005) yang menyatakan bahwa dalam penelitian kualitatif ini terdapat sumber data utama berupa kata-kata dan tindakan, selebihnya dokumen milik perusahaan sebagai data tambahan. Sumber data yang penulis gunakan dalam menyusun penelitian ini, diperoleh langsung dari lokasi penelitian yakni Kantor dan Cold Storage PT. Cowboy Nusantara Jaya. Berdasarkan apa yang dikemukakan Moleong (2004) perlu adanya penetapan fokus yang jelas dimana penulis dengan tepat memutuskan dari sekian banyak data yang berhasil dikumpulkan, data mana yang akan digunakan atau dibuang. Penulis memutuskan untuk menggunakan dua jenis data dalam menyusun penelitian ini yakni data primer dan sekunder.

Untuk memperoleh data primer penulis menggunakan teknik wawancara mendalam (indepth interview) bersama tiga informan, yakni Direktur utama PT. Cowboy Nusantara Jaya, Karyawan, dan salah satu konsumen. Sebelum melakukan wawancara mendalam penulis menyusun daftar beberapa pertanyaan atau interview 
guide. Pemilihan ketiga informan dilakukan berdasarkan teknik purposive sampling. Berdasarkan pendapat Kriyantono (2006) bahwa teknik purposive sampling merupakan beberapa orang yang terpilih berdasarkan seleksi dengan pertimbangan dasar kriteria tertentu yang disesuaikan dengan tujuan penelitian.

Data sekunder penulis dapatkan secara tidak langsung dengan beberapa perantara seperti bukti catatan, atau laporan milik perusahaan dalam bentuk arsip atau dokumen (Sugiyono: 2013). Penulis mendapatkan data sekunder dengan teknik telaah dokumen/ dokumen tertulis. Data tersebut berupa laporan milik perusahaan, foto dokumentasi, hasil studi/riset, teori yang relevan, buku yang berkaitan dengan topik pembahasan. Setelah data hasil penelitian disajikan, kemudian teknik yang digunakan penulis dalam mengidentifikasi dan menganalisis data menggunakan Matriks strategi SWOT dalam mengelola reputasi untuk memenangkan persaingan bisnis. Matriks SWOT ini dapat menggambarkan dengan bagaimana peluang serta ancaman eksternal yang dihadapi perusahaan disesuaikan dengan kekuatan dan kelemahan yang dimiliki perusahaan. Matrik ini dapat menghasilkan empat kemungkinan alternatif strategis.

\begin{tabular}{|c|c|c|}
\hline $\begin{array}{l}\text { IFAS } \\
\text { EFAS }\end{array}$ & $\begin{array}{l}\text { STRENGTS (S) } \\
\text { faktor kekuatan } \\
\text { internal }\end{array}$ & $\begin{array}{l}\text { WEAKNESS (W) } \\
\text { faktor kelemahan } \\
\text { internal }\end{array}$ \\
\hline $\begin{array}{l}\text { OPPORTUNITIES } \\
\text { (O) } \\
\text { faktor peluang } \\
\text { eksternal }\end{array}$ & $\begin{array}{l}\text { STRATEGI SO } \\
\text { Ciptakan strategi yang } \\
\text { menggunakan kekuatan } \\
\text { untuk memanfaatkan } \\
\text { peluang }\end{array}$ & $\begin{array}{l}\text { STRATEGI WO } \\
\text { Ciptakan strategi yang } \\
\text { meminimalkan } \\
\text { kelemahan untuk } \\
\text { memanfaatkan peluang }\end{array}$ \\
\hline $\begin{array}{l}\text { THREATHS }(\mathrm{T}) \\
\text { faktor ancaman } \\
\text { eksternal }\end{array}$ & $\begin{array}{l}\text { STRATEGI ST } \\
\text { Ciptakan strategi yang } \\
\text { menggunakan kekuatan } \\
\text { untuk mengatasi } \\
\text { ancaman }\end{array}$ & $\begin{array}{l}\text { STRATEGI WT } \\
\text { Ciptakan strategi yang } \\
\text { meminimalkan } \\
\text { kelemahan dan } \\
\text { menghindari ancaman }\end{array}$ \\
\hline
\end{tabular}

\section{Hasil Penelitian}

Penelitian langsung dilakukan di Kantor dan Cold Storage PT. Cowboy Nusantara Jaya yang terletak di Jalan Kampus No. 643 Rt.002 Rw. 007, Grendeng, 
Kecamatan Purwokerto Utara, Kabupaten Banyumas- Jawa Tengah. Sebelum penulis datang ke lokasi penelitian, penulis terlebih dahulu menghubungi pihak PT. Cowboy Nusantara Jaya. Penelitian ini dilaksanakan pada hari Jumat, 14 Juni 2019 dimulai pada pukul 09.00 WIB. Sebagai awal perkenalan penulis kepada PT. Cowboy Nusantara Jaya, pemilik perusahaan memperkenalkan logo perusahaan terlebih dahulu sebagai berikut:

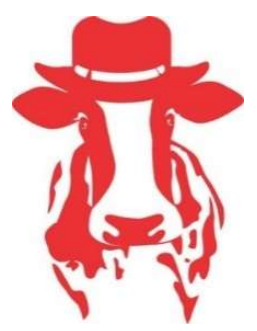

Gambar 1. Logo PT. Cowboy Nusantara Jaya

Pada wawancara tersebut, pemilik perusahaan menceritakan awal berdirinya PT. Cowboy Nusantara Jaya. Perusahaan ini merupakan anak cabang dari PT. Suri Nusantara Jaya yang berdiri pada tahun 2016 yang berada di wilayah Jawa Tengah tepatnya di kota Purwokerto, Kabupaten Banyumas. PT. Cowboy Nusantara Jaya merupakan perusahaan yang bergerak dalam bisnis impor daging yang berasal dari Australia dan India. Perusahaan ini dipimpin oleh seorang wanita muda sukses berumur 26 tahun yang menjabat sebagai direktur utama dari PT. Cowboy Nusantara Jaya, yakni Nugrahaning Dyah Larasati, S.E. PT. Cowboy Nusantara Jaya memiliki visi dan misi perusahaan antara lain, sebagai berikut:

a. Visi PT. Cowboy Nusantara Jaya adalah menjadi perusahaan yang menjayakan karyawannya dan bermanfaat untuk masyarakat.

b. Misi PT. Cowboy Nusantara Jaya antara lain:

- Bekerja dengan ikhlas untuk memberikan pelayanan terbaik kepada pelanggan dengan harga yang rasional

- Memiliki SDM yang profesional, jujur dalam perkataan dan perbuatan 
- Mensejahterakan karyawan sesuai dengan tanggung jawab dan attitude dari setiap individu.

Berikut merupakan struktur organisasi PT. Cowboy Nusantara Jaya, antara lain:

- Direktur Utama : Nugrahaning Dyah Larasati, S.E.

- Marketing : Rubianto \& Tumino

- Admin : Nur

- Kepala Gudang : : Bobi

- Staf Gudang $\quad$ : Cholil, Trio, dan Kayim

- Supir : Kamto dan Anton

PT. Cowboy Nusantara Jaya saat ini memiliki tiga cold storage. Di Purwokerto sendiri terdapat dua cold storage yang beralamat di Jl. Kampus No. 643 Purwokerto dan di Watumas, Purwanegara, Purwokerto Utara (Cafe Mom milk) serta satu cold storage lagi di Purbalingga tepatnya di Dusun 2, Majasari, Bukateja, Purbalingga.

Berdasarkan hasil wawancara, Pemilik PT. Cowboy Nusantara Jaya memperkirakan masing-masing cold storage dapat menyimpan produk daging sapi impor kurang lebih 12-50 ton. Direktur PT. Cowboy Nusantara Jaya dibantu oleh sembilan karyawan yang dimilikinya untuk mengatasi kepentingan pemasaran produk, pengelolaan kantor dan cold storage oleh admin dan staf lainnya, serta pendistribusian produk daging impor.

Menurut pelanggan yang berhasil penulis wawancarai, mereka merasa telah puas dengan pelayanan yang diberikan oleh perusahaan. Proses pemesanan yang sangat mudah dapat dilakukan "by phone", dilanjutkan dengan pembayaran via transfer, dan barang dikirimkan kepada buyer. Proses pendistribusian produk langsung dilakukan oleh staf gudang dan supir. Pendistribusian produk dilakukan baik ke luar kota dan dalam wilayah Purwokerto dengan ketentuan satu kali pengiriman dengan armada mobil box memuat minimal 20kg daging untuk wilayah Purwokerto. Untuk pengiriman produk ke luar kota minimal memuat $100 \mathrm{~kg}$ daging sapi impor. Berikut penulis sajikan 
data penguat berupa tabel rekap harian pemesanan daging sapi impor pada PT. Cowboy Nusantara Jaya :

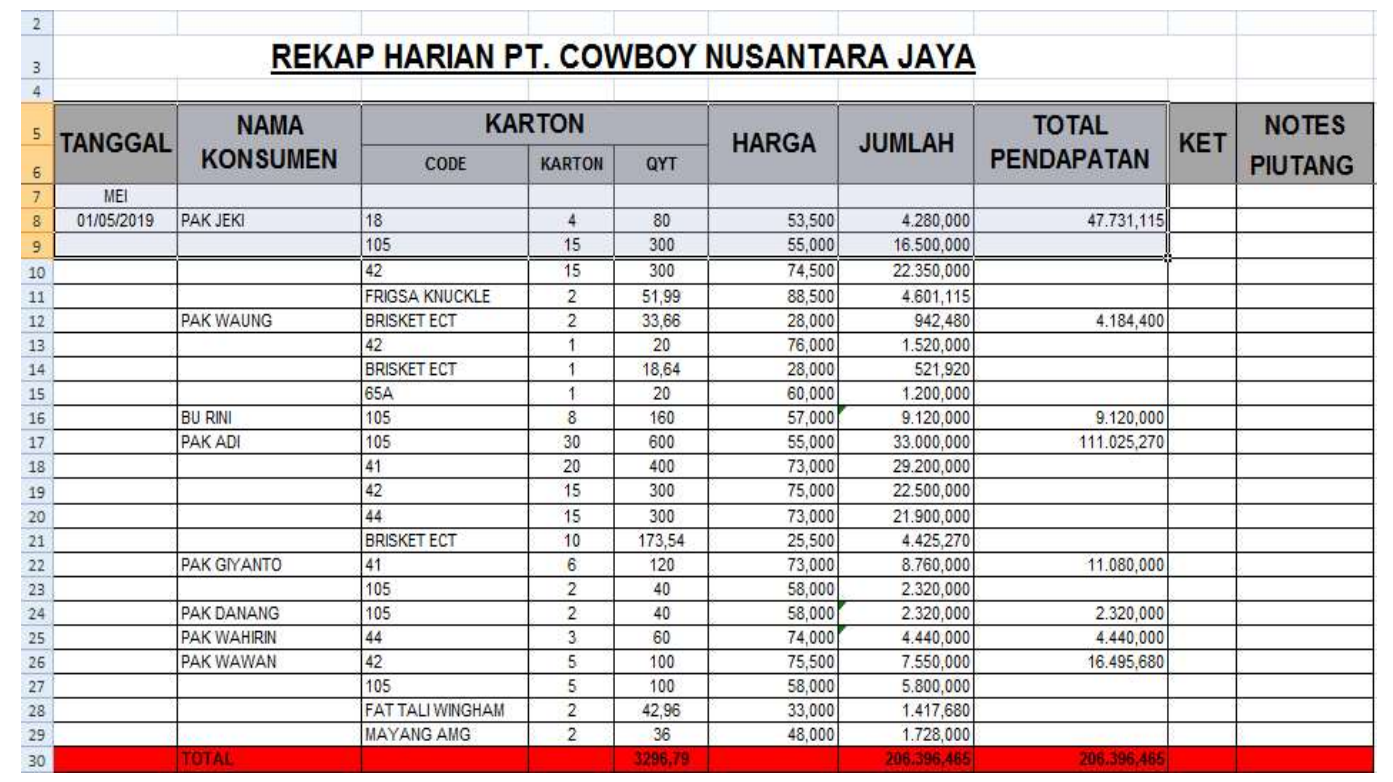

Tabel 1. Rekap Harian Penjualan PT. Cowboy Nusantara Jaya 1 mei 2019

PT. Cowboy Nusantara Jaya memiliki beragam pilihan daging sapi dengan kualitas impor yang baik. Perusahaan ini telah memiliki sistem kontrol yang baik untuk mengetahui stok daging yang ada di ketiga cold storage. Hal ini betujuan agar dapat memnuhi kebutuhan pelanggan dan permintaan di pasaran, bahkan pengecekan stok akan dilakukan setiap hari. Sebagai contoh berikut adalah stok daging PT. Cowboy Nusantara Jaya per tanggal 26 Juni 2019:

\begin{tabular}{|r|l|l|}
\hline No & Nama Produk & Jumlah \\
\hline 1. & FQ11 & $3684,6 \mathrm{~kg}$ \\
\hline 2. & FQ18 & $120 \mathrm{~kg}$ \\
\hline 3. & FQ64 & $4600 \mathrm{~kg}$ \\
\hline 4. & FQ65 & $2940 \mathrm{~kg}$ \\
\hline 5. & FQ67 & $1037 \mathrm{~kg}$ \\
\hline
\end{tabular}




\begin{tabular}{|c|c|c|}
\hline 6. & FQ105 & $2300 \mathrm{~kg}$ \\
\hline 7. & FQ105A & $8040 \mathrm{~kg}$ \\
\hline 8. & HQ31 & $1006,8 \mathrm{~kg}$ \\
\hline 9. & HQ41 & $1758,5 \mathrm{~kg}$ \\
\hline 10. & HQ42 & $2782,1 \mathrm{~kg}$ \\
\hline 11. & HQ44 & $2419,9 \mathrm{~kg}$ \\
\hline 12 & HQ45 & $1110,4 \mathrm{~kg}$ \\
\hline 13. & HQ46 & $1000 \mathrm{~kg}$ \\
\hline 14. & Backrip meramis & $122,52 \mathrm{~kg}$ \\
\hline 15 & Brisket bortwich & $0 \mathrm{~kg}$ \\
\hline 16. & Brisket ect & $1191,96 \mathrm{~kg}$ \\
\hline 17. & Brisket oakey & $15,23 \mathrm{~kg}$ \\
\hline 18 . & Brisket kilkoy & $367,3 \mathrm{~kg}$ \\
\hline 19. & Daging paket india & $0 \mathrm{~kg}$ \\
\hline 20. & Daging paket australi & $0 \mathrm{~kg}$ \\
\hline 21 . & Frigsa knuckle & $26,31 \mathrm{~kg}$ \\
\hline 22 . & Frigsa eye round & $207,75 \mathrm{~kg}$ \\
\hline 23 & Fat lem wingham & $351,05 \mathrm{~kg}$ \\
\hline 24. & Fat tali wingham & $2637,46 \mathrm{~kg}$ \\
\hline 25 . & Hm ibp & $6067,78 \mathrm{~kg}$ \\
\hline 26. & Hm swift & $136,1 \mathrm{~kg}$ \\
\hline 27. & Jantung ect & $0 \mathrm{~kg}$ \\
\hline 28. & Lips amg & $25 \mathrm{~kg}$ \\
\hline 29. & Leg bone oakey & $996,28 \mathrm{~kg}$ \\
\hline 30 . & Mayang amh & $0 \mathrm{~kg}$ \\
\hline 31 . & Paru amh & $70,55 \mathrm{~kg}$ \\
\hline 32. & Silverside & $54,91 \mathrm{~kg}$ \\
\hline
\end{tabular}




\begin{tabular}{|r|l|l|}
\hline 33. & Shortrib ect & $236,72 \mathrm{~kg}$ \\
\hline 34. & Topside carnemax & $878,55 \mathrm{~kg}$ \\
\hline 35. & Trot ect & $413,4 \mathrm{~kg}$ \\
\hline 36. & Trot amh & $27,2 \mathrm{~kg}$ \\
\hline 37. & Tendon ralph & $901,75 \mathrm{~kg}$ \\
\hline 38 & $50 c l$ barco & $150 \mathrm{~kg}$ \\
\hline 39 & $65 c l$ wmpg & $27,2 \mathrm{~kg}$ \\
\hline 40. & $65 c l$ meramis & $81,6 \mathrm{~kg}$ \\
\hline 41. & cuberol angus & 4 slice \\
\hline 42. & cuberol wagyu & 5 slice \\
\hline 43. & tenderloin angus & 5 slice \\
\hline 44. & tenderloin wagyu & 5 slice \\
\hline 45. & striploin angus & 5 slice \\
\hline 46. & striploin wagyu & 5 slice \\
\hline 47. & knuckle wagyu & 5 slice \\
\hline
\end{tabular}

Tabel 2. Rekapan Harian Stok Produk PT. Cowboy Nusantara Jaya 26 Juni 2019

PT. Cowboy Nusantara Jaya berhasil menembus ke pasaran dengan merangkul banyak pelanggaan dari jenis usaha yang beragam. Kebanyakan dari pelanggan PT. Cowboy Nusantara Jaya ini merupakan pedagang daging di pasar, pemilik rumah potong hewan, penyetok restoran, café, hotel, UMKM kuliner, dan pedagang kecil rumahan. Untuk itu perlu kiranya PT. Cowboy Nusantara Jaya selalu berupaya untuk menjaga kualitas produk yang dimilikinya agar mampu bersaing dengan para kompetitor. Selain itu, perusahaan ini selalu berupaya untuk menjaga keseimbangan harga produknya dengan harga daging di pasaran. Berdasarkan pernyataan pemilik PT. Cowboy Nusantara Jaya, pihaknya selalu menjaga kualitas dan harga produk yang paling utama, karena apabila selisih 500 Rupiah saja pelanggan bisa saja berpaling ke 
perusahaan lain. Harga daging sapi di pasaran tidak dapat stabil karena dapat berubah sewaktu-sewaktu tergantung bagaimana permintaan dan ketersediaan barang. Berikut ini adalah daftar harga produk daging sapi impor PT. Cowboy Nusantara Jaya pertanggal 26 juni 2019:

\begin{tabular}{|l|l|l|}
\hline No & Nama Produk & Harga Produk \\
\hline $\mathbf{1 .}$ & FQ11 & Rp. 70.000 \\
\hline $\mathbf{2 .}$ & FQ18 & Rp. 68.000 \\
\hline $\mathbf{3 .}$ & FQ64 & Rp. 85.000 \\
\hline $\mathbf{4 .}$ & FQ65 & Rp. 80.000 \\
\hline $\mathbf{5 .}$ & FQ67 & Rp. 73.000 \\
\hline $\mathbf{6 .}$ & FQ105 & Rp. 70.000 \\
\hline $\mathbf{7 .}$ & FQ105A & Rp. 57.000 \\
\hline $\mathbf{8 .}$ & HQ31 & Rp. 84.000 \\
\hline $\mathbf{9 .}$ & HQ41 & Rp. 86.000 \\
\hline $\mathbf{1 0 .}$ & HQ42 & Rp. 88.000 \\
\hline $\mathbf{1 1 .}$ & HQ44 & Rp. 85.000 \\
\hline $\mathbf{1 2 .}$ & HQ45 & Rp. 79.000 \\
\hline $\mathbf{1 3 .}$ & HQ46 & Rp. 77.000 \\
\hline $\mathbf{1 4 .}$ & Topside carnermax & Rp. 87.000 \\
\hline $\mathbf{1 5 .}$ & Brisket & Rp. 28.000 \\
\hline $\mathbf{1 6 .}$ & Legbone & Rp. 16.000 \\
\hline $\mathbf{1 7 .}$ & Fat tali & Rp. 29.000 \\
\hline $\mathbf{1 8 .}$ & Fat lem & Rp. 34.000 \\
\hline $\mathbf{1 9}$ & Troot ect 46.000 \\
\hline
\end{tabular}

Tabel 3. Update Harga PT. Cowboy Nusantara Jaya 26 Juni 2019 
Analisis pertama merupakan analisis yang terdiri dari Strength (Kekuatan) dan Weakness (Kelemahan) yang penulis dapatkan dari wawancara mendalam dengan Direktur Utama PT. Cowboy Nusantara Jaya.

Strength (Kekuatan), antara lain:

1. Reputasi induk perusahaan, PT. Suri Nusantara Jaya yang baik.

2. PT. Cowboy Nusantara Jaya memiliki 3 rumah penyimpanan untuk menyimpan stok daging.

3. Produk daging sapi yang berkualitas.

4. Kapasitas produksi yang besar.

Weakness (Kelemahan), antara lain:

1. Belum optimal dalam memenuhi permintaan konsumen.

2. Jarak tempat produksi yang jauh menyebabkan pengiriman stock terhambat.

Analisis kedua merupakan analisis yang terdiri dari Opportunity (Peluang) dan Threat (Ancaman) yang penulis dapatkan dari wawancara mendalam dengan Direktur Utama PT. Cowboy Nusantara Jaya.

Opportunity (Peluang), antara lain:

1. PT. Cowboy Nusantara Jaya bekerja sama dengan mitra bisnis usaha kecil dan pemerintah setempat.

2. Permintaan produk yang terus meningkat.

3. Hubungan yang baik dengan konsumen.

4. Berinovasi dengan menjual produk melalui market place.

Threat (Ancaman), antara lain:

1. Kenaikan harga daging sewaktu-waktu dari perusahaan pusat.

2. Perubahan nilai-tukar rupiah.

Dibawah ini merupakan matriks strategi SWOT berdasarkan data yang telah penulis dapatkan di PT. Cowboy Nusantara Jaya: 


\begin{tabular}{|c|c|c|}
\hline Faktor Internal & $\begin{array}{l}\text { Strength (S) } \\
\text { 1. } \\
\text { Reputasi induk } \\
\text { perusahaan yang siap } \\
\text { melayani pelanggan } \\
\text { kapanpun dan } \\
\text { dimanapun dengan } \\
\text { kualitas produk daging } \\
\text { sapi yang baik serta } \\
\text { harga produk yang } \\
\text { bersaing dengan } \\
\text { pasaran (grosir). } \\
\text { Memiliki } 3 \text { rumah } \\
\text { penyimpanan stock } \\
\text { daging di Purwokerto } \\
\text { (2) yaitu di Grendeng\& } \\
\text { Watumas serta } \\
\text { Purbalingga yaitu di } \\
\text { Majasari, Bukateja (1). } \\
\text { Kapasitas produksi } \\
\text { yang besar dengan } \\
\text { minimal muatan } 12 \text { - } \\
\text { 28 ton dalam sekali } \\
\text { pengiriman. } \\
\text { 3. }\end{array}$ & $\begin{array}{l}\text { Weakness (W) } \\
\text { 1. Tidak dapat memastikan } \\
\text { ketersediaan barang guna } \\
\text { memenuhi permintaan } \\
\text { konsumen. } \\
\text { 2. Jarak tempat produksi } \\
\text { yang jauh menyebabkan } \\
\text { pengiriman stock } \\
\text { terhambat yaitu dari } \\
\text { Bekasi ke Purwokerto. }\end{array}$ \\
\hline $\begin{array}{l}\text { Opportunity (O) } \\
\text { 1. PT. Cowboy Nusantara } \\
\text { Jaya bekerja sama } \\
\text { dengan mitra bisnis }\end{array}$ & $\begin{array}{l}\text { Strength Opportunity (SO) } \\
\text { 1. Meningkatkan reputasi } \\
\text { dan kualitas SDM } \\
\text { dengan merekrut staf } \\
\text { untuk perusahaan }\end{array}$ & $\begin{array}{l}\text { Weak Opportunity (WO) } \\
\text { 1. Mencari cara agar dapat } \\
\text { memantau dan } \\
\text { memastikan ketersediaan } \\
\text { barang agar dapat }\end{array}$ \\
\hline
\end{tabular}




\begin{tabular}{|c|c|c|}
\hline $\begin{array}{l}\text { usaha kecil dan } \\
\text { pemerintah setempat. } \\
\text { 2. Permintaan produk } \\
\text { yang terus meningkat. } \\
\text { 3. Hubungan yang baik } \\
\text { dengan konsumen } \\
\text { melalui pelayanan } \\
\text { yang cepat dan ramah. } \\
\text { 4. Berinovasi dengan } \\
\text { menjual produk } \\
\text { melalui market place } \\
\text { seperti Tokopedia. }\end{array}$ & $\begin{array}{l}\text { minimal kualifikasi } \\
\text { pendidikan D3. } \\
\text { 2. Mempermudah sistem } \\
\text { penjualan dengan } \\
\text { menggunakan market } \\
\text { place guna } \\
\text { meringankan biaya } \\
\text { marketing dan } \\
\text { meningkatkan } \\
\text { permintaan. } \\
\text { 3. } \\
\text { Meningkatkan kualitas } \\
\text { kebersihan ruang } \\
\text { penyimpanan stock } \\
\text { daging dengan rutin } \\
\text { mensterilkan ruangan } \\
\text { penyimpanan setiap } 1 \\
\text { minggu 3x. }\end{array}$ & $\begin{array}{l}\text { memperbaiki kualitas } \\
\text { pelayanan untuk } \\
\text { konsumen seperti dengan } \\
\text { menambah sistem } \\
\text { berbasis online yang } \\
\text { tersambung dengan } \\
\text { perusahaan induk guna } \\
\text { memastikan jumlah stok } \\
\text { daging yang dapat } \\
\text { dikirim setiap harinya. } \\
\text { (misalnya aplikasi) } \\
\text { Menambah armada baru } \\
\text { yaitu } 5 \text { unit mobil box } \\
\text { guna mempercepat proses } \\
\text { pengiriman stock daging } \\
\text { ke mitra bisnis. }\end{array}$ \\
\hline $\begin{array}{l}\text { 1. Kenaikan harga daging } \\
\text { sewaktu-waktu dari } \\
\text { perusahaan pusat. } \\
\text { 2. Perubahan nilai-tukar } \\
\text { rupiah. }\end{array}$ & $\begin{array}{l}\text { Strength Threats (ST) } \\
\text { 1. Melalui reputasi yang } \\
\text { baik, PT. Cowboy } \\
\text { Nusantara Jaya harus } \\
\text { meningkatkan minat } \\
\text { distributor dari luar } \\
\text { daerah Purwokerto, } \\
\text { seperti Purbalingga, } \\
\text { Cilacap, Banjarnegara } \\
\text { dan daerah lain di }\end{array}$ & $\begin{array}{l}\text { Weakness Threats (WT) } \\
\text { 1. Menetapkan harga yang } \\
\text { terjangkau dengan tetap } \\
\text { mempertahankan kualitas } \\
\text { daging impor yang segar, } \\
\text { sehat, aman, dan halal. } \\
\text { 2. Meningkatkan jenis } \\
\text { daging yang sedang tren } \\
\text { di pasaran dan belum ada } \\
\text { di Purwokerto guna } \\
\text { menarik simpatik dan }\end{array}$ \\
\hline
\end{tabular}




\begin{tabular}{|l|l|l|}
\hline & seputaran & minat dari konsumen \\
Barlingmascakeb. & untuk mau membeli \\
2. Mengantisipasi & produk daging sapi dari \\
kemungkinan kenaikan & PT. Cowboy Nusantara \\
harga dengan sistem & Jaya. \\
penjualan yang & \\
meringankan biaya & \\
seperti memberikan & \\
potongan harga khusus & \\
untuk pelanggan. & \\
\hline
\end{tabular}

Tabel 4. Matriks SWOT

Ada semacam paradoks yang berkembang dalam pengelolaan reputasi, bahwa semakin dibutuhkan, reputasi cenderung semakin sulit untuk dikelola. Yang jelas, kehilangan reputasi yang baik jauh lebih mudah terjadi pada suatu perusahaan jika dibandingkan dengan upaya yang dilakukan dalam membangun reputasi. Strategi yang dinilai paling tepat digunakan untuk melaksanakan suatu rencana dalam pengembangan perusahaan PT. Cowboy Nusantara Jaya sesuai dengan pendapat yang dikemukakan Fambrun. Dalam hal ini kaitannya dengan manajemen reputasi antara lain dengan:

1. Memberikan produk dengan kualitas baik dengan harga yang bersaing. Untuk menjaga kepercayaan konsumen, PT. Cowboy Nusantara Jaya tetap memberikan produk dengan kualitas terbaik yakni:

1. Kualitas daging yang segar secara bentuk, warna, dan aroma

2. Menjaga kebersihan dan keamanan daging: daging dipastikan dalam kondisi bersih dan aman dikonsumsi dengan tidak mengandung penyakit atau zat yang berbahaya bagi manusia.

3. Kandungan gizi yang sehat seperti protein, lemak, vitamin, 
4. Serta jaminan produk daging halal mengingat penduduk Kabupaten Banyumas didominasi oleh muslim.

2. Selalu berupaya memberikan pelayanan yang cepat dan pasti bagi pelanggan.

1. Pelayanan tercepat ini bertujuan agar memberikan kesan aman dan nyaman bagi pelanggan. Para pelanggan dipermudah dengan proses "order by phone" dan transaksi pembelian dapat dilakukan via transfer.

2. Barang segera dikirim ke tempat pelanggan sesuai dengan pesanan yang telah dibuat.

3. Melakukan operasi pasar secara berkala, yang bertujuan agar dapat mengendalikan harga produk di pasaran. PT. Cowboy bekerjasama dengan pemerintah melalui Dinas terkait seperti Dinas Perindustrian dan Perdagangan Kabupaten Banyumas, Dinas Perikanan dan Peternakan dan pihak lainnya untuk menyelenggarakan kegiatan operasi pasar. Kegiatan ini dilakukan oleh PT. Cowboy Nusantara Jaya secara berkala maupun pada saat terjadi kenaikan perminataan daging yang signifikan yakni pada saat menjelang hari besar seperti lebaran dan tahun baru.

4. Mengembangkan bisnis ke daerah atau kota lain.

PT. Cowboy Nusantara Jaya perlu memperluas segmentasi penjualannya dengan melihat peluang-peluang di kota sekitaran Kabupaten Banyumas seperti Cilacap, Purbalingga, Banjarnegara, dan Bumiayu.

5. PT. Cowboy Nusantara Jaya berinovasi dengan menjual produk daging sapi impor melalui market place seperti shopee, tokopedia dll dengan tujuan memperluas pasar, menekan biaya promosi, dan memberikan pelayanan yang mudah, cepat, dan aman bagi pelanggan.

6. Mulai merancang strategi corporate social responsibility guna menjaga reputasi. 
PT. Cowboy Nusantara Jaya sebagai badan usaha yang secara regulasi telah berbentuk perseroan terbatas tentu terikat undang-undang yang berlaku. Salah satunya berkewajiban untuk melaksanakan program Corporate Social Responsibility sebagai wujud kepedulian perseroan terhadap masyarakat atau lingkungan sebagai sebuah komitmen. Hal ini didasarkan pada bab V Pasal 74 Undang-undang Nomor 40 Tahun 2007 tentang Perseroan Terbatas mengatur mengenai Tanggung Jawab Sosial dan Lingkungan. Program CSR yang dapat dilaksanakan adalah memberikan pelatihan atau sosialisasi kepada pelaku UMKM kuliner tentang daging sehat dan cara mengelola daging menjadi masakan yang sehat dan enak.

\section{Kesimpulan}

Pemenuhan kebutuhan dan permintaan daging di Indonesia, khususnya di Kabupaten Banyumas masih belum dapat terpenuhi. Hal tersebut terjadi pada waktuwaktu tertentu seperti lebaran dan tahun baru yang tentu saja berdampak pada lonjakan harga dipasaran. PT. Cowboy Nusantara Jaya merupakan anak cabang perusahaan PT. Suri Nusantara Jaya yang bergerak dalam bisnis impor daging sapi yang menyediakan berbagai macam jenis daging yang diimpor dari India dan Australia. Kualitas produk yang di jual oleh PT. Cowboy Nusantara Jaya bisa dibilang sama dengan yang sudah beredar di masyarakat saat ini, namun bisa di katakan bahwa permintaan pasar jauh lebih banyak. Sehingga perusahaan ini bisa mengirimkan daging empat kali dalam satu minggu. Dengan pelayanan yang cepat, serta kualitas daging yang baik tentu saja secara otomatis membuat reputasi PT. Cowboy Nusantara Jaya baik di mata pelanggan. Hal ini haruslah dipertahankan karena jika reputasi perusahaan yang sudah baik ini tidak dijaga, maka akan menimbulkan kerugian bagi perusahaan. Oleh karena itu, dalam mengelola reputasi tersebut diperlukan adanya strategi prioritas. Karena reputasi akan berjalan pararel dengan kualitas produk dan pelayanan, menurut Fambrun. Adapun 
strategi yang bisa digunakan untuk menjaga reputasi perusahaan tersebut adalah dengan:

1. Memberikan produk dengan kualitas baik dengan harga yang bersaing. Untuk menjaga kepercayaan konsumen, PT. Cowboy Nusantara Jaya tetap memberikan produk dengan kualitas terbaik dengan selalu menjaga jaminan daging impor yang sehat, aman, bergizi dan halal.

2. Selalu berupaya meningkatkan pelayanan yang ramah, cepat, dan nyaman untuk pelanggan. Hal ini akan senantiasa menjaga reputasi yang baik bagi PT. Cowboy Nusantara Jaya di mata pelanggan.

3. Menggandeng beberapa pihak termasuk dinas terkait setempat, BUMN dll untuk melakukan operasi pasar secara berkala pada waktu-waktu tertentu sebagai upaya menekan harga daging di pasar agar tetap terjangkau.

4. Berinovasi dengan menjual produk melalui market place seperti shopee, tokopedia dll sebagai wujud peningkatan pelayanan kepada pelanggan dan memperluas segmentasi penjualan dengan meminimalisir besarnya biaya pemasaran produk.

\section{Saran}

Dalam penulisan artikel ini, sebagai penutup penulis ingin memberikan saran yang ditujukan kepada PT. Cowboy Nusantara Jaya sebagai perusahaan yang bergerak di bidang impor daging sapi. Adapun saran yang bisa penulis berikan untuk menjadi bahan pertimbangan bagi PT. Cowboy Nusantara Jaya dalam merancang strategi pengelolaan reputasi adalah dengan mulai mencoba untuk mengembangkan bisnis tersebut ke kota lain seperti Purbalingga, Cilacap dan Banjarnegara yang berada di sekitar Banyumas. Apalagi mengingat bahwa salah satu cold storage PT. Cowboy Nusantara Jaya berada di kota Purbalingga. Adapun hal lain yang bisa dijadikan sebagai bahan masukan untuk PT. Cowboy Nusantara Jaya adalah untuk mulai merancang program corporate social responsibility guna memenuhi kewajiban atas 
dasar hukum yang mengikat yakni UU Nomor 40 Tahun 2007. Selain itu program CSR akan menjaga reputasi perusahaan yang sudah baik seperti saat ini.

\section{Daftar Pustaka}

Ardianto, Elvinaro. (2013). Handbook of Public Relations: Pengantar Komprehensif. Bandung: Simbiosa Rekatama Media.

Baines, Paul, John Egan \& Frank Jefkins. (2004). Public Relations Contemporary Issues and Techniques. United Kingdom: Elsevier.

Dick, Alan, Dipankar Chakravarti and Gabriel Biehal. (1990). Memory Based Inference during Cunsumer Choice. Journal of Consumer Research, Volume 17

Fombrun, C., and Shanley, M. (1990). What in a Name? Reputation Building and Corporate Strategy. Academy of Management Journal, Volume 33

Ferrel, O.C and D, Harline. (2005). Marketing Strategy. South Western: Thomson Corporation

Gitosudarmo, Indriyo. (2001). Manajemen Strategis. Yogyakarta: BPFE-Yogyakarta.

Hakiki Sirait, W.H. Limbong dan Suryahadi. (2007). Analisis Strategi Pemasaran Daging Sapi pada CV. Duta Mandiri Abadi. Jurnal MPI. Vol. 2.

Herbig, Paul, John Milewicz and Jim Golden. (1994). A Model of Reputation Building and Destruction, Journal of Business Research, Volume 31.

Kriyantono, Rachmat. (2006). Teknik Praktis Riset Komunikasi. Jakarta: Kencana

Mulyana, Deddy. (2018). Metodologi Penelitian Kualitatif Paradigma Baru Ilmu Komunikasi dan Ilmu Sosial Lainnya. Bandung: PT. Remaja Rosdakarya.

Moleong, Lexy J. (2004). Metodologi Penelitian Kualitatif. Bandung: PT. Remaja Rosdakarya.

Moleong, Lexy J. (2005). Metodologi Penelitian Kualitatif. Bandung: PT. Remaja Rosdakarya.

Morley, Michael. (2002). How To Manage Your Global Reputation: A Guide To The Dynamics of International Public Relations. New York: Palgrave. 
Muslimah, Nuzul Azmi. (2015). Strategi Pengembangan Usaha Pemasaran Daging Sapi (Bos taurus) di Kecamatan Kuala Simpang Kabupaten Aceh Tamiang. AGRISAMUDRA. Vol.2. Universitas Samudra, Langsa-Aceh.

Peraturan Menteri Pertanian No. 59/ Permentan/HK.060/8/2007 tentang Percepatan Pencapaian Swasembada Daging Sapi (P2SDS).

Rangkuti, F. (1998). Analisa SWOT Teknik Membedah Kasus Bisnis. Jakarta: Gramedia Pustaka Utama.

Rurkinantia, Aisa. Rina Oktaviani, Rina. Sanim, Bunasir. (2017). Strategi Pengembangan Bisnis Pemotongan Sapi. Jurnal Aplikasi Bisnis dan Manajemen Vol. 3 Sekolah Bisnis, Institut Pertanian Bogor.

Safitri, Dini. (2014). Analisis SWOT Prodi DIII Humas FIS UNJ. Communicology: Jurnal Ilmu Komunikasi, Vol.2 No.2 Pp.22-41

Sugiyono. (2013). Metode Penelitian Kuantitatif, Kualitatif dan R\&D. Bandung: CV. Alfabeta 